\title{
Egg production of Baltic cod (Gadus morhua) in relation to variable sex ratio, maturity, and fecundity
}

\author{
Gerd Kraus, J onna Tomkiewicz, and Friedrich W. Köster
}

\begin{abstract}
Observed fluctuations in relative fecundity of Eastern Baltic cod (Gadus morhua L.) were related to food availability during the main feeding period and were used to develop a predictive model that explained $72 \%$ of the interannual variations in fecundity. Time series of sex ratios, maturity ogives, and relative fecundity were combined with mean weights-at-age and stock sizes from an analytical multispecies model to estimate the potential egg production (PEP). Relationships between PEP and independent estimates of realized daily and seasonal egg production from egg surveys were highly significant. The difference between estimates of potential and realized seasonal egg production was of a magnitude corresponding to the expected loss of eggs as a result of atresia, fertilization failure, and early egg mortality. The removal of interannual variability in sex ratio, maturity, and fecundity on estimates of PEP deteriorated the relationships in all three cases. PEP proved to be superior to spawning stock biomass as measure of the reproductive potential in a stock-recruitment relationship of Eastern Baltic cod. PEP in combination with the reproductive volume explained $61 \%$ of the variation in year-class strength at age 2 .
\end{abstract}

Résumé : Les fluctuations observées dans la fécondité relative de la morue franche (Gadus morhua L.) dans l'est de la Baltique ont pu être reliées à la disponibilité de la nourriture durant la période principale d'alimentation et elles ont servi à établir un modèle prédictif qui explique $72 \%$ de la variation de la fécondité d'une année à une autre. Des séries temporelles des rapports mâles:femelles, des ogives de maturité et de la fécondité relative combinées à des données de masses moyennes pour un âge donné et de taille des stocks obtenues d'un modèle analytique multispécifique ont permis d'estimer la production potentielle d'oeufs (PEP). Les relations entre PEP et les estimations indépendantes de production journalière et saisonnière d'oeufs obtenues à partir des inventaires d'oeufs sont hautement significatives. La différence entre les estimations de la production saisonnière potentielle d'oeufs et celles de la production réalisée sont d'un ordre de grandeur qui correspond aux pertes qu'on peut attendre de l'atrésie, de l'absence de fécondation et de la mortalité précoce des oeufs. Le retrait de la variation annuelle du rapport mâles:femelles, de la maturité ou de la fécondité du modèle d'estimation de PEP affaiblit la relation dans les trois cas. PEP s'avère être une meilleure mesure du potentiel reproducteur que ne l'est la biomasse du stock des reproducteurs dans la relation stock-recrutement de la morue de l'est de la Baltique. PEP, en combinaison avec le volume reproducteur, explique $61 \%$ de la variation de l'importance de la classe d'âge de 2 ans.

[Traduit par la Rédaction]

\section{Introduction}

Stock-recruitment relationships are used in the assessment of many marine fish stocks to define biological reference points and to conduct medium- to long-term predictions, though they may often not adequately forecast cohort sizes. Mathematical expressions including dome-shaped (Ricker 1954) and asymptotic (Beverton and Holt 1957) curves or more flexible functions (Shepherd 1982) have commonly been assigned to describe this essential relationship. In most cases, a large residual variance within stock-recruitment relationships remains. Explanations for poor correlation include a lack of good quality data, autocorrelation in time series, environmentally induced variation in fertilization success, egg and juvenile life-stage survival affecting recruitment, or failure of stock indices to reflect the true reproductive potential (e.g., Rothschild 1986).

In stock assessment, the spawning stock biomass (SSB) has been widely applied as an index of the stock reproductive potential assuming proportionality between the SSB and

Received 27 November 2001. Accepted 21 November 2002. Published on the NRC Research Press Web site at http://cjfas.nrc.ca on 10 January 2003.

$\mathrm{J} 16635$

G. Kraus ${ }^{1}$ and F.W. Köster. ${ }^{2}$ Institute of Marine Sciences, Düsternbrooker Weg 20, D-24105 Kiel, Germany.

J. Tomkiewicz. ${ }^{3}$ Danish Institute for Fisheries Research, Kavalergaarden 6, DK-2920 Charlottenlund, Denmark.

${ }^{1}$ Corresponding author (e-mail: gkraus@ifm.uni-kiel.de).

${ }^{2}$ Present address: Danish Institute for Fisheries Research, Charlottenlund Castle, DK-2920 Charlottenlund, Denmark.

${ }^{3}$ Present address: Institute of Marine Sciences, Düsternbrooker Weg 20, D-24105 Kiel, Germany. 
the egg production. However, evidence is increasing that the SSB is not a reliable estimator of reproductive potential (Marshall et al. 1998, 1999; Köster et al. 2003). The SSB estimates in stock-recruitment relationships are often derived from combined female and male maturity data or even an adult knife-edge maturity (e.g., age 3+) and do not account for sex-specific differences in maturity or skewed sex ratios. Furthermore, interannual variations in size-specific or relative fecundity can be substantial owing to changes in growth and nutritional condition (Kjesbu et al. 1998; Kraus et al. 2000; Lambert and Dutil 2000), and differences in the quality of offspring depending on adult stock structure add further variability (Trippel et al. 1997; Marteinsdottir and Thorarinsson 1998). Traditional biological reference points do not consider this variation in reproductive potential, and thus, the stock resiliency to exploitation may be overestimated (Murawski et al. 2001).

In many fish stocks, time series of abiotic and biotic factors needed to study population dynamics are scarce or the data quality poor, though experiments sometimes provide a theoretical background. As a result, key factors and processes influencing reproduction and recruitment success have been difficult to identify. In the central Baltic Sea, however, the amount of data related to cod reproduction and recruitment as well as environmental variability is comprehensive. A series of studies have been conducted to separately examine processes influencing developmental success of subsequent life stages to assess interactive processes and evaluate their specific contribution to recruitment variability (MacKenzie et al. 1996; Köster et al. 2001a). Within this framework, the present study focuses on improving indices of the reproductive potential of Eastern Baltic cod. We introduce potential egg production by the spawning stock, investigate the reliability of this approach by comparing the data sets with observed egg abundance in the field, test the significance of interannual variation in applied data series, and examine the performance of improved reproductive potential estimates in the stock-recruitment relationship.

The potential egg production of cod (Gadus morhua) in the presently only important spawning area in the central Baltic, i.e., the Bornholm Basin, was computed on the basis of area and quarter specific stock abundance estimates and mean weight-at-age from a multispecies assessment model. Area-specific time series of sex ratios and the proportion of mature females (maturity ogives) were applied to estimate the female SSB. Observed and modeled time series of relative fecundity were used to compute the potential egg production. Two scenarios based on observed and predicted relative fecundity, respectively, were compared with the realized daily and seasonal egg production derived from ichthyoplankton surveys. The effect of removing annual variability in sex ratios, maturity ogives, and relative fecundity on the correlation between the potential and realized egg production was examined by successively setting one of these input variables constant in the calculations and comparing the results with the realized egg production. Finally, whether the potential egg production and the reproductive volume (Pliksh et al. 1993; MacKenzie et al. 2000) could improve the SSB as measure of reproductive potential in stock-recruitment relationships was tested.

\section{Materials and methods}

Stock size, weight-at-age, sex ratios, and maturity ogives

Stock abundance of cod in the Bornholm Basin, International Council for the Exploration of the Sea (ICES) Subdivision 25 (see ICES code), was obtained from an areadisaggregated multispecies virtual population analysis (MSVPA) (Köster et al. 2001b), updated by ICES (2001a) to cover the period 1976 to 1999 . The abundance and biological characteristics of the species incorporated in the MSVPA differ between areas of the presently applied assessment unit of the stock. Therefore, the MSVPA runs were performed on the basis of quarterly and subdivision-specific catch and weight-at-age data provided by ICES (1999, 2001b).

Area-specific time series of sex ratios and the proportion of mature females at age were derived from a database including $\sim 15000$ records from national and international trawl surveys in ICES Subdivision 25 (Tomkiewicz et al. 1997; ICES 1998). Annual estimates of sex ratios and female maturity ogives were used for the years 1988 to 1998, whereas 5-year averages were used for the previous period 1976-1987 because of less intensive sampling. The average of the years 1996-1998 was applied for 1999.

\section{Fecundity estimates and establishment of time series}

Estimates of relative fecundity were available for 19761978 and 1983-1984 from Shapiro (1988), for 1994-1995 from Bleil and Oeberst (1996), and for 1987-1992 and 1996 from Kraus et al. (2000). In addition, 199 ovaries sampled in ICES Subdivision 25 from 1998-2000 were analyzed in the present study using the methods described in Kraus et al. (2000). Fecundity and relative fecundity as used below refer to the potential fecundity, defined as total number of developing oocytes and the number per gram female total body weight, respectively.

Neither individual fecundity data nor measures of variance (prerequisites for statistical analysis) were included in Shapiro (1988) and Bleil and Oeberst (1996). Therefore, the following analyses were carried out on a subset of data based on the Bornholm Basin samples 1987-1992 and 1996 from investigations presented in Kraus et al. (2000) and from the present study. To ensure that annual average relative fecundity is not biased by fish weight, the relationships between fecundity and weight were tested for linearity and the intercepts were tested for deviation from zero. To examine linearity, log-log regressions of individual fecundity versus total body weight were conducted and the slopes were tested against one. Secondly, the intercepts of the untransformed linear relationships were tested for deviation from zero by applying $t$ tests. As a further test, the residuals of the annual fecundity body weight relationships were regressed against total length and the slope was tested for significance to ensure that the relative fecundity was also independent of female length.

Interannual variations in annual average relative fecundity were tested for significance, as between-year variations were already documented by Kraus et al. (2000). One-way analysis of variance (ANOVA) and a subsequent multiple comparison of means (Tukey's honestly significant difference test for unequal sample sizes (HSD); Sokal and Rohlf 1995) 
Table 1. Acronyms for time series on reproductive potential including fecundity, female spawning stock biomass, and potential and realized egg production.

\begin{tabular}{lll}
\hline Time series & Abbreviation & Years included \\
\hline Observed relative fecundity & ORF & $1976-1978 ; 1983-1984 ; 1987-1992 ; 1994-1996 ; 1998-2000$ \\
Predicted relative fecundity & PRF & $1976-2000$ \\
Female spawning stock biomass & FSSB & $1976-1999$ \\
Potential egg production & PEP & \\
$\quad$ Based on ORF & PEP (ORF) & $1976-1978 ; 1983-1984 ; 1987-1992 ; 1994-1996 ; 1998-1999$ \\
Based on PRF & PEP (PRF) & $1976-1999$ \\
$\quad$ Constant sex ratio & - & $1976-1978 ; 1983-1984 ; 1987-1992 ; 1994-1996 ; 1998-1999$ \\
$\quad$ Constant maturity & - & $1976-1978 ; 1983-1984 ; 1987-1992 ; 1994-1996 ; 1998-1999$ \\
$\quad$ Constant fecundity & - & $1976-1999$ \\
Realized daily egg production & RDEP & $1987-1988 ; 1991 ; 1993-1994 ; 1996 ; 1999$ \\
Realized seasonal egg production & RSEP & $1976-1978 ; 1983 ; 1985-1996 ; 1998-1999$ \\
\hline
\end{tabular}

Note: For potential egg production, five data sets were computed using different input variables. —, no abbreviation available.

were conducted to ascertain the significance of interannual differences in relative fecundity.

Two different strategies were approached to obtain time series of relative fecundity. One data series, consisting solely of observed relative fecundity (ORF, Table 1), included data from Shapiro (1988), Bleil and Oeberst (1996), Kraus et al. (2000), and the present study. As this series is incomplete, an alternative time series of predicted relative fecundity (PRF, Table 1) was established, based on relationships between relative fecundity from the same data set as in the above interannual analysis and the following predictor variables: $(a)$ a prey availability index, $P_{\mathrm{i}}$, calculated as the ratio of unit cod SSB to unit sprat (all age groups) plus herring (age groups 0-2) biomass in ICES Subdivision 25 in the fourth quarter preceding the spawning period (obtained from the above MSVPA); and (b) ambient winter water temperatures in ICES Subdivision 25 in the fourth quarter preceding the spawning period. The ambient temperature was calculated as the average temperature of the water layer deeper than $55 \mathrm{~m}$, i.e., below the halocline, using data extracted from the ICES hydrographic database. Relationships between annual average relative fecundities and the predictor variables as well as the interaction of the independent variables were evaluated by minimizing the least squares of various univariate linear and nonlinear regression equations.

\section{Potential egg production}

Stock sizes were adjusted to peak spawning time, defined as the middle of the second quarter for the period 19761989 and the start of third quarter during 1990-1999 to consider a shift in spawning time (Wieland et al. 2000). The sex ratio and female maturity time series were applied to the stock abundance to calculate the female spawning stock size. Data for weight-at-age from quarter two and three according to the above-described periods were used to determine the female SSB (FSSB, Table 1). Relative fecundity data series, i.e., ORF and PRF, were applied to the corresponding FSSB to obtain two alternative time series of the potential egg production (PEP, Table 1). To assess the effects of removing variability in the time series of sex ratio, maturity, and relative fecundity, three additional series of PEP were constructed and compared with the realized egg production (see below). All series applied the ORF as fecundity estimator, but with the sex ratio, maturity ogive, or ORF successively held constant. The constant sex ratio and maturity ogive were calculated as average per age over all years of the time series, whereas for constant fecundity, the average of the ORF series was applied.

\section{Realized egg production and evaluation}

The time series of FSSB and PEP estimates were compared with independent time series of the realized egg production derived from the observed cod egg abundance in the Bornholm Basin (Table 1). Egg surveys covered the entire spawning area of $\sim 11800 \mathrm{~km}^{2}$ consisting of 32 to 45 stations on a $10 \times 10$ nautical mile (n.mi) grid. Station specific abundances $/ \mathrm{m}^{2}$ were averaged over all stations covered and raised to the total spawning area.

The egg production estimates used by Köster et al. (2001a) applied abundance estimates of the youngest egg stage (IA) for the years 1987-1996. To prolong the time series, it was necessary to use stage I as the finest resolution, because the separation into substages IA and IB was not initiated until 1985. Consequently, the daily egg production was calculated as the abundance of stage I eggs divided by the stage duration estimated from stage-specific egg development temperature relationships (Wieland 1995). The ambient temperatures used in the relationships were derived from the ICES hydrographic database for Subdivision 25 in the second or third quarters, applying a model to predict the relative vertical distribution of cod eggs. In this model, empirical vertical egg distributions are related to water density profiles by fitting a parabolic function to the log relative distribution (Köster et al. 2001a). In contrast to Köster et al. (2001a), dead eggs that could not be assigned to a specific stage were distributed proportionally to the relative stage-specific distribution of live eggs in the samples to estimate the total realized egg production (total amount of spawned eggs) rather than the viable production.

To obtain yearly values of the realized daily egg production (RDEP), survey-specific estimates were averaged over a 3 -month period encompassing the main spawning period, i.e., April-June up to 1989, May-July from 1990-1992, and June-August from 1993-1999, to account for the shift in the spawning time. The RDEP was calculated for years with a minimum coverage of three surveys including 1976-1978, 1983, 1985-1996, and 1998-1999 and used as an index of the realized seasonal egg production (Table 1). 
In a smaller number of years the coverage of the spawning period with egg surveys allowed for estimation of the realized seasonal egg production (RSEP) based on survey-specific daily production of the youngest egg stage (IA). Only years in which the spawning season was covered by at least six egg surveys were considered, i.e., 1987-1988, 1991, 19931994, 1996, and 1999 (Table 1). According to Daan (1981), daily cod egg production of the youngest egg stage is normally distributed over time. A transformation to natural logarithms converts these normal distributions into parabolas. Based on this assumption, we fitted second-order polynomials to the transformed survey-specific daily egg production for each year by applying the least-squares method. To obtain the RSEP, the area beneath the fitted curves was estimated by numerical integration of retransformed data.

To evaluate the effect of removing variability in the variables used to estimate PEP, the PEP based on ORF and the three manipulated PEP time series were regressed against RDEP and RSEP and explained variances were compared. The influence of different measures of the reproductive potential on recruitment was examined by comparing the SSB, PEP, and PEP in combination with the reproductive volume (MacKenzie et al. 2000) to numbers of recruits at age 2 for the period 1976 to 1999. Estimates of SSB and recruitment for the entire Eastern Baltic cod stock were obtained from the standard assessment by ICES (2002) applying extended survivor analysis. PEP was scaled to the entire stock using $(i)$ areaspecific stock sizes for ICES Subdivisions 25, 26, and 28 from the MSVPA, i.e., covering the main spawning areas, (ii) corresponding sex ratios and sex-specific maturity data from the database of Tomkiewicz et al. (1997) and ICES (1998), and (iii) area-specific PRF applying the respective input data to the fecundity model. The sum of PEP over the three spawning grounds yielded a total stock estimate of PEP. Data on reproductive volume (i.e., the volume of water in which salinity, oxygen, and temperature conditions permit successful cod egg development) for each spawning site were adopted from MacKenzie et al. (2000). Simple and multiple linear regression were applied to test the ability of PEP and the reproductive volume to improve SSB as measure of the reproductive potential in a stock-recruitment relationship.

\section{Results}

Linear relationships fitted between fecundity and total body weight were highly significant for each sampling year $\left(r^{2}=\right.$ 0.72 in 1988 to $r^{2}=0.98$ in 1999; Table 2). Deviation from linearity was insignificant for 8 out of 10 years as evidenced by the slopes of $\log -\log$ regressions, which did not differ significantly from one. Of the 2 years with significant deviations, 1989 was close to the fixed probability level of 0.05 , whereas the deviation from linearity was larger in 1991 (Table 2). The intercepts of the untransformed fecundity - body weight relationships were not significantly different from zero, except in 1989 when significance indicated a violation of isometry (Table 2). The residuals of these relationships were in none of the years significantly related to fish length $(p>0.05$; Table 2). As no systematic violation of the assumptions was observed, relative fecundity was considered to be independent of body size. Average relative fecundity

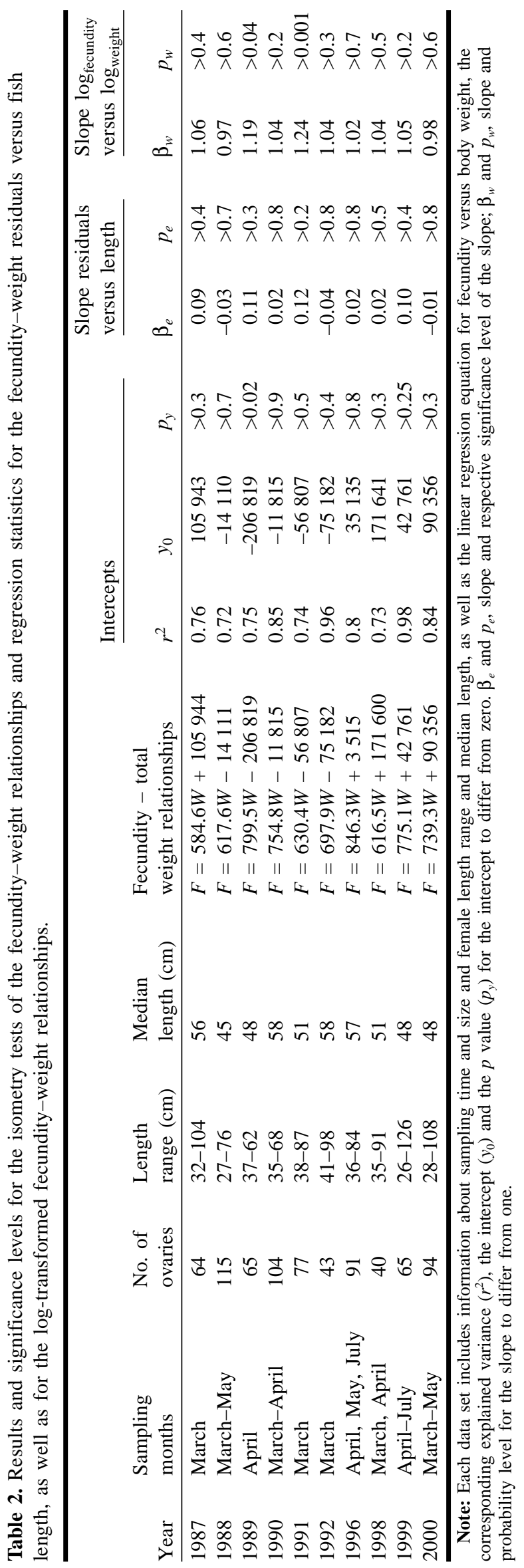

(C) 2002 NRC Canada 
Fig. 1. Annual average relative fecundity of Baltic cod (Gadus morhua) in International Council for the Exploration of the Sea (ICES) Subdivision 25 based on data from Kraus et al. (2000) and the present study. The vertical bars represent approximations of the $95 \%$ confidence limits of Tukey's honestly significant difference test for unequal sample sizes.

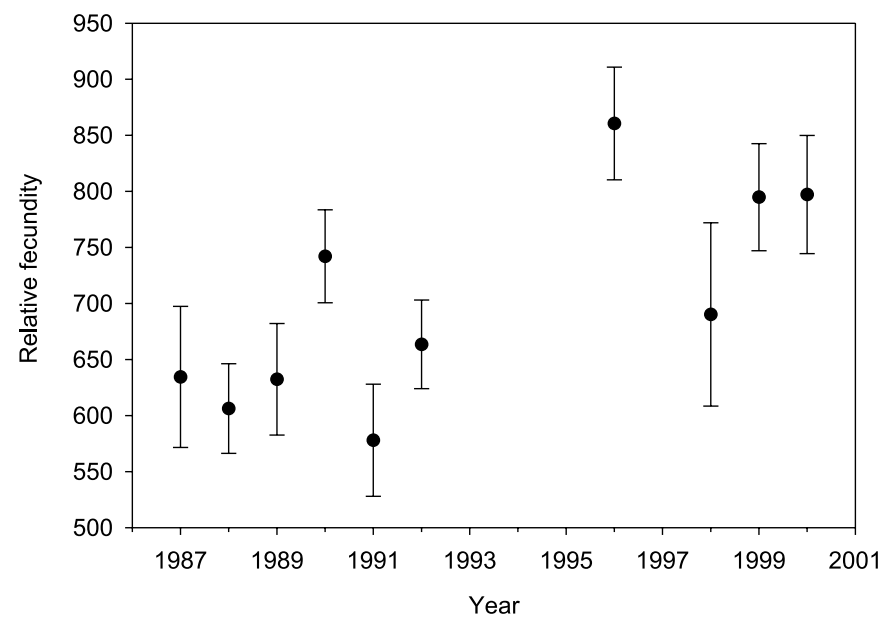

varied significantly between years (ANOVA, $p<0.01$ ). The highest relative fecundity was observed in 1996, and the lowest in 1991 (Tukey's HSD test, $p<0.001$; Fig. 1), amounting to a difference of $33 \%$ (maximum set to $100 \%$ ).

A simple model to predict relative fecundity was successfully established applying the relative fecundity estimated from the above data subset and the prey availability. The best fit to data was obtained with an exponential two-parameter function $\left(r^{2}=0.72 ; p=0.01\right.$; Fig. 2$)$,

$$
\mathrm{PRF}_{y}=\exp \left(6.23+0.02 P_{\mathrm{i} y}\right)
$$

where $\mathrm{PRF}_{y}$ is the predicted relative fecundity and $P_{\mathrm{i} y}$ is the prey availability index of year $y$. The best fit between water temperature and fecundity was parabolic $\left(r^{2}=0.21 ; p=\right.$ 0.18 ), with the highest relative fecundities occurring at intermediate water temperatures. This relationship was, however, nonsignificant $(\alpha=0.05)$, though a significant linear interaction between $P_{\mathrm{i} y}$ and water temperature was revealed $\left(r^{2}=\right.$ $0.31 ; p=0.047)$. Consequently, water temperature was not included in the prediction model and the above exponential model was used to establish the time series of PRF. The model reflected the ORF including the independent fecundity data from Shapiro (1988) and Bleil and Oeberst (1996) quite well except for two years (1978 and 1983), where the data points were outside the prediction limits (Fig. 2). Both PRF and ORF time series were positively correlated $\left(r^{2}=\right.$ $0.55 ; p<0.05)$. The maximum difference was detected in 1983, with the PRF being $61 \%$ higher than ORF, but ORF showed an even larger difference to the subsequent year in the ORF time series. A similar pattern was observed for 1978, though less pronounced (Fig. 3a).

The FSSB and PEP follow the general stock development in ICES Subdivision 25 with a historic maximum in the early 1980s followed by a pronounced decline from mid1980 s to late 1990 s, with an intermediate peak in the mid1990s (Fig. 3b). The PEP (PRF) ranged from $0.75 \times 10^{13}$ to $4.41 \times 10^{13}$, whereas PEP (ORF) varied between $0.69 \times 10^{13}$ and $4.26 \times 10^{13}$. The time series agreed well except for the
Fig. 2. Relative fecundity in relation to the prey availability index, $P_{\mathrm{i}}$ (sprat + herring age- 0 and age- 2 biomass per unit of mature cod), in International Council for the Exploration of the Sea (ICES) Subdivision 25. 9 , data used to fit the model; $\bigcirc$, independent data from Shapiro (1988) and Bleil and Oeberst (1996). The solid line represents the two-parameter exponential model curve, the dotted lines represent the $95 \%$ confidence limits, and the broken lines represent the prediction limits.

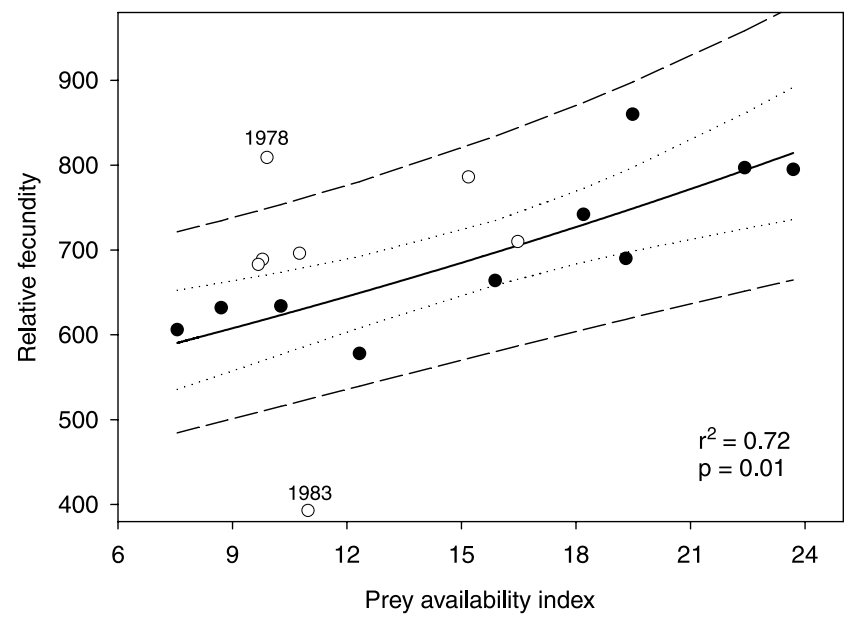

deviating years 1978 and 1983 in the ORF time series, which are reflected in the PEP (ORF).

The estimates of RDEP at main spawning time ranged from a minimum of $2.19 \times 10^{10}$ in 1992 to a maximum $24.9 \times 10^{10}$ in 1994 (Fig. $3 c$ ). The pronounced differences in the level of RDEP with low estimates in 1987 and 1999 and a high estimate in 1994 were also captured by the RSEP, with the latter being on average two orders of magnitude higher than daily production values. The underlying relationships to estimate the RSEP were significant $(\alpha=0.05)$ for all included years (Fig. 4), with relatively large proportions of the observed variation being explained by the fitted curves $\left(r^{2}=0.83\right.$ in 1999 and 0.98 in 1996). The correlation between RDEP and RSEP was also highly significant $\left(r^{2}=\right.$ $0.98 ; p<0.001)$. The RDEP was therefore considered a reliable index of the RSEP and used as an extended data series in the comparisons with PEP.

The variability of the RDEP and RSEP corresponded to the variation in the FSSB and PEP time series based on PRF as well as on ORF (Figs. 5a-5f). Applying RSEP in the relationships resulted in higher coefficients of determination, although the degrees of freedom were considerably lower, but with the significance of RDEP relationships being highest (Figs. $5 a, 5 c, 5 e$ ). Patterns were similar for both RDEP and RSEP. The application of the PEP (ORF) as index of the potential egg production in the relationship explained the highest proportion of the variation in the realized egg production, whereas FSSB explained the least and the coefficients of determination related to PEP (PRF) were at an intermediate level. The difference between PEP (ORF) and RSEP represents an index for the loss of eggs from the final maturation stage (applied for the fecundity analyses) to earliest embryonic phase (egg stage IA). Determining the loss from the slope of the regression between RSEP and PEP (ORF) (Fig. 5f) resulted in an estimated reduction of potential fecundity of $58 \%$, whereas the simple ratio between RSEP and 
Fig. 3. (a) Average relative fecundity (ORF; $\boldsymbol{\square}$, data from own investigations; $\boldsymbol{\Delta}$, data from Shapiro (1988) and Bleil and Oeberst (1996); PRF predicted from eq. 1), as well as corresponding prey availability index, $P_{\mathrm{i}}$, in relation to time. (b) The corresponding time series of female spawning stock biomass (FSSB), potential egg production estimates based on the two different fecundity series (PEP/ORF and PEP/PRF). (c) Realized daily egg production (RDEP) and realized seasonal egg production (RSEP) in International Council for the Exploration of the Sea (ICES) Subdivision 25.
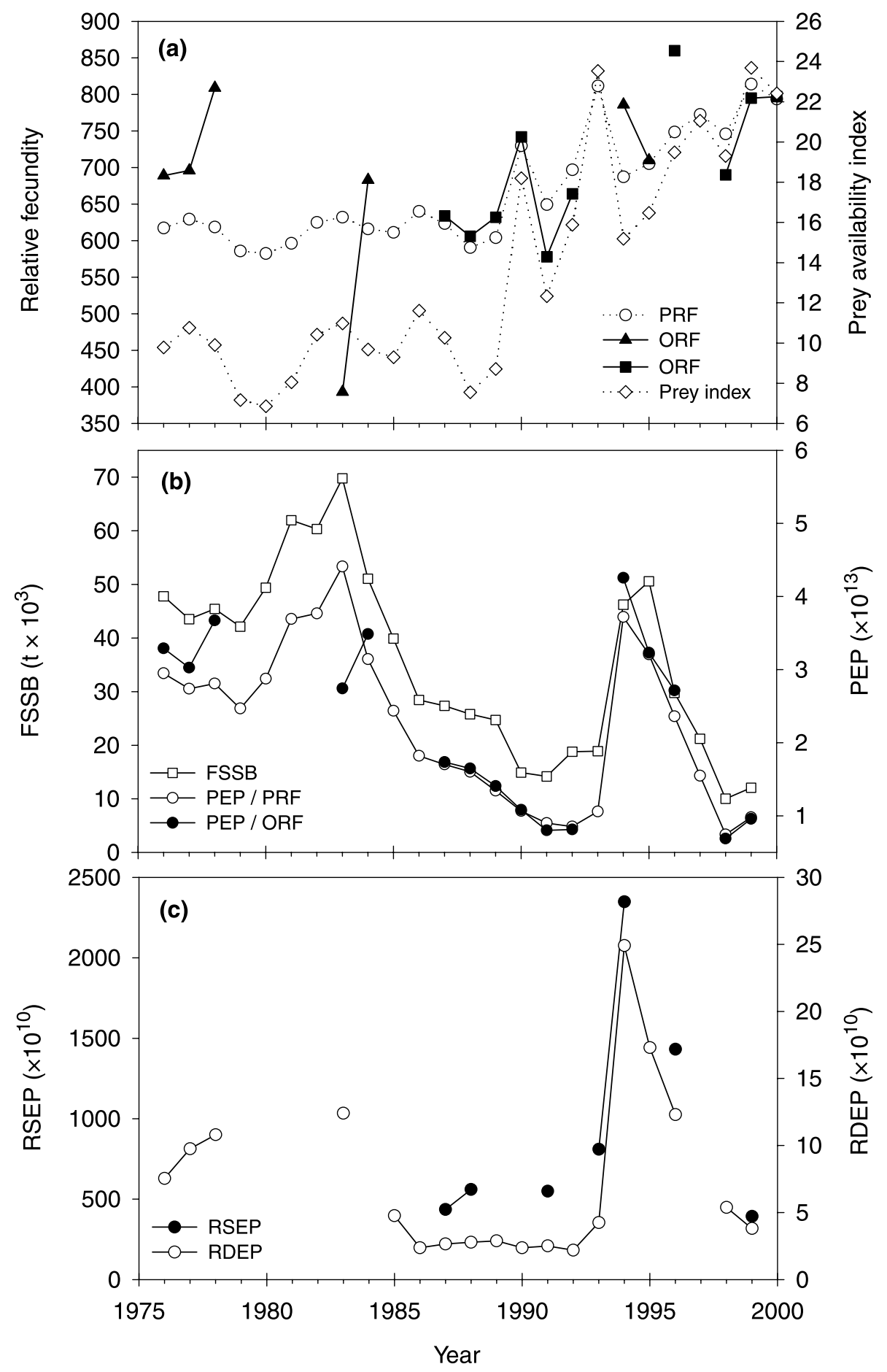

PEP (ORF) was on average 0.46 , corresponding to an egg loss of $54 \%$.

Removal of the variability in sex ratio, maturity, and relative fecundity from PEP deteriorated the relationships to the realized egg production. The coefficients of determination of the linear relationships between the three manipulated PEP series and RDEP and RSEP were substantially lower than the $r^{2}$ of the corresponding relationships with the unmanipulated PEP (ORF) time series (Table 3). The highest impact on the relationship with RDEP and RSEP was observed when the temporal variability in female maturity was removed. The application of a constant maturity ogive reduced the $r^{2}$ by $34 \%$ for RDEP and by $44 \%$ for RSEP, the latter with a loss of significance $(\alpha=0.05)$. Keeping the rel- 
Fig. 4. Daily production of youngest egg stage (IA) transformed to natural logarithms over Julian day in different years: (a) 1987, (b) 1988, (c) 1991, (d) 1993, (e) 1994, ( f ) 1996, and ( $g$ ) 1999. The symbols represent the date-specific production estimates and the curves represent second-order polynomials fitted to data. The realized seasonal egg production (RSEP) is determined from the area under the curve.
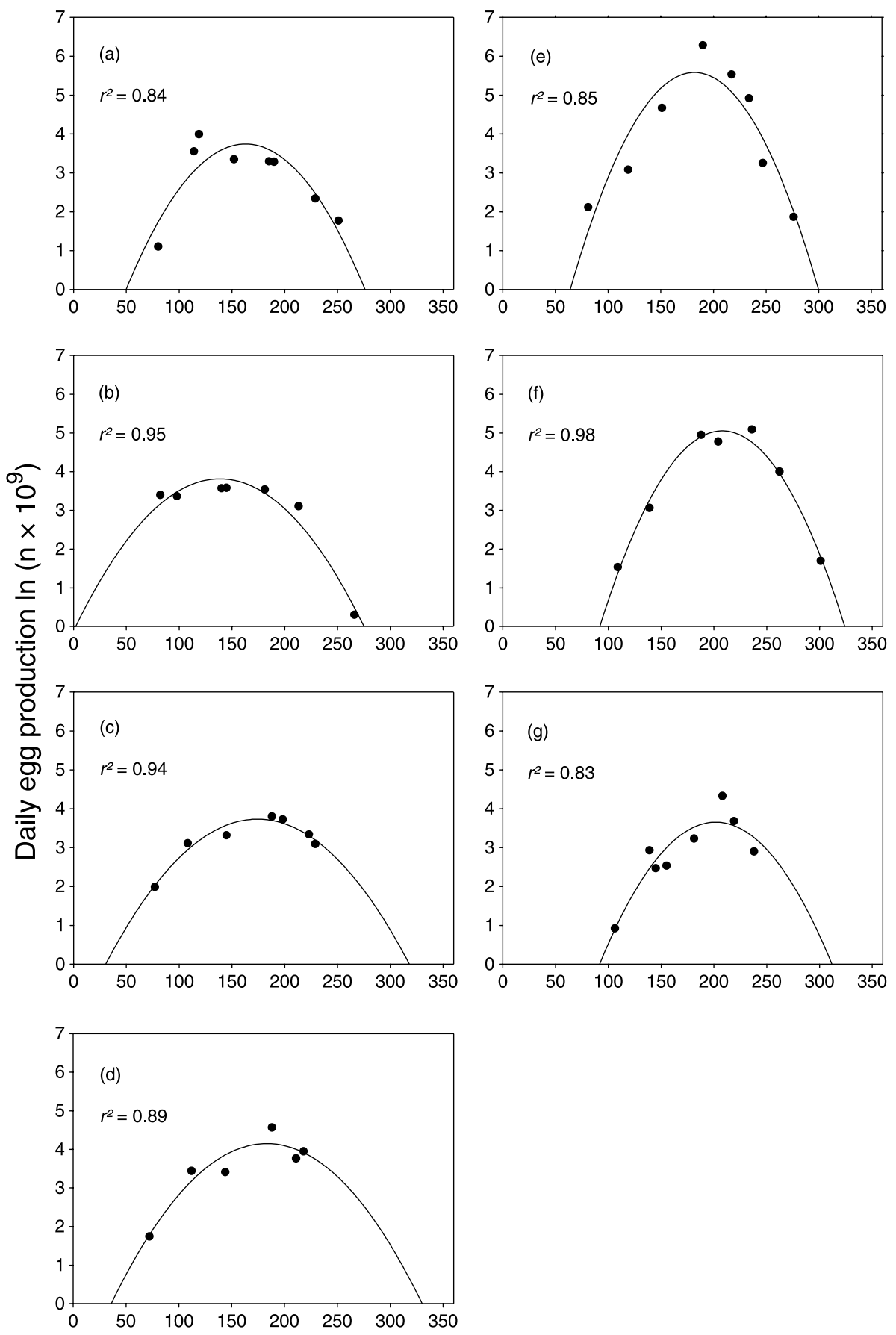

Julian day

ative fecundity constant reduced the percent explained variation by 17 and $10 \%$ for RDEP and RSEP, respectively, whereas constant sex ratios resulted in a reduction of $5 \%$ in the explained variation for both relationships.

Linear regression of recruits versus SSB explained $32 \%$ of the variation in recruitment at age 2 , with relatively clustered data points at low SSB (Fig. 6a). SSB captured the trend, but large positive residuals were present in the 1970s at high SSB levels, whereas residuals were mainly negative from 1982 to 1989 as well as during the mid-1990s (Fig. 6b). Substitution of SSB by PEP (PRF) increased the explained variance to $43 \%$. However, the pattern with clustered data at low egg production, a trend towards positive residuals at high egg production, and negative residuals during the de- 
Fig. 5. Relationships between the realized egg production (RDEP and RSEP) and different indices of the reproductive potential, as well as explained variation and significance levels for linear regressions. The RDEP and RSEP are plotted versus $(a)$ and $(b)$ female spawning stock biomass (FSSB); $(c)$ and $(d)$ potential egg production (PEP) based on predicted relative fecundity (PRF); and $(e)$ and (f) PEP based on observed relative fecundity (ORF). $\bigcirc$, observed values; lines, linear regressions.
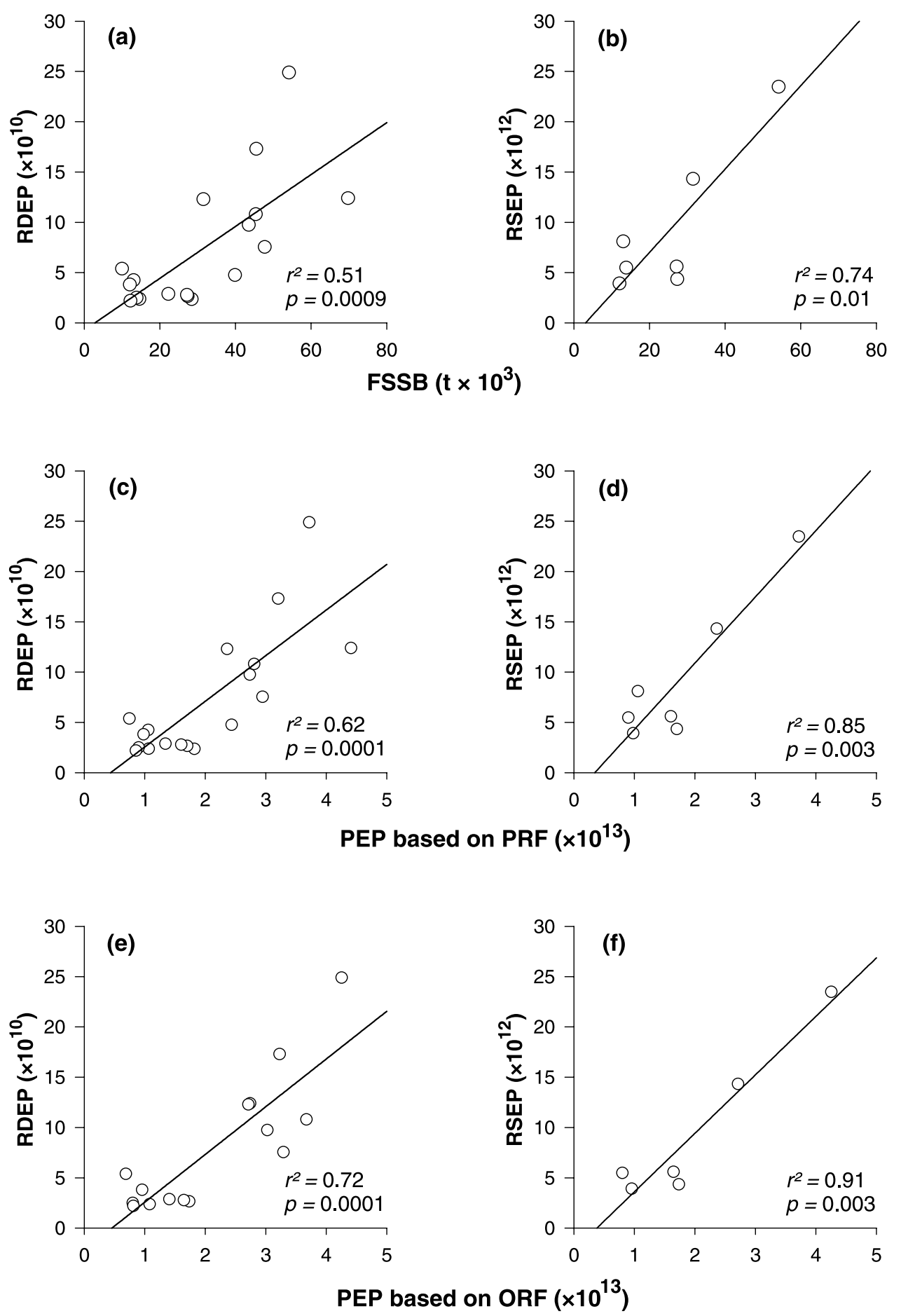

clining phase and at low levels of PEP remained (Figs. $6 c$, $6 d)$. The most substantial improvement of the stock-recruitment relationship was achieved applying the PEP and the reproductive volume in a multiple linear regression explaining $61 \%$ of the variation in recruitment (Fig. 6e). Although large residuals were observed for 1979, 1983, and 1994 and the scatter at low stock levels, i.e., during the 1990s, remained relatively large (Fig. 6f), this model captured the trend in re- cruitment considerably better than the previous attempts, especially at the high stock levels during the 1970s.

\section{Discussion}

For batch spawning fish species, the realized egg production derived from egg surveys combined with information on individual fecundity has commonly been used to estimate 
Table 3. Coefficients of determination and corresponding probability values for relationships of potential egg production (PEP) with constant maturity, fecundity, and sex ratio versus realized daily (RDEP) and seasonal (RSEP) egg production. Reference relationships of potential egg production based on observed data versus RDEP and RSEP are also given.

\begin{tabular}{llcc}
\hline PEP & & RDEP & RSEP \\
\hline Observed data & $r^{2}$ & 0.72 & 0.91 \\
& $p$ & $<0.001$ & $<0.005$ \\
Constant maturity ogive & $r^{2}$ & 0.38 & 0.47 \\
& $p$ & $<0.05$ & 0.13 \\
Constant relative fecundity & $r^{2}$ & 0.55 & 0.81 \\
& $p$ & $<0.005$ & $<0.05$ \\
Constant sex ratio & $r^{2}$ & 0.67 & 0.86 \\
& $p$ & $<0.001$ & $<0.01$ \\
\hline
\end{tabular}

SSB by applying egg production methods (e.g., Alheit 1993). In the present study, the potential egg production (PEP) estimated from the FSSB and relative fecundity is compared with the realized egg production derived from egg abundance data. The degree to which both estimates will correspond depends on the loss of eggs from late vitellogenesis to early embryogenesis as well as on the accuracy of the estimates. However, the variability imposed on this relationship is limited compared with a traditional stock-recruitment relationship. With this in mind, the RSEP was used as an independent estimate of the egg production to evaluate the applicability of different PEP time series. As the RSEP data points were few, the complementing RDEP was used as an index to increase the number of observations and, thereby, ascertain the relationships between PEP and the realized egg production.

The average relative fecundity was independent of length and constant over the whole range in body weight and, thus, considered to be a reliable estimator of the egg production per unit FSSB. However, the relative fecundity varied significantly between years, which confirmed the results of Kraus et al. (2000). Interannual variation in size-specific or relative fecundity has also been demonstrated for other Atlantic cod stocks, e.g., the Northwest Atlantic (Pinhorn 1984), the North Sea (Rijnsdorp et al. 1991), and the Northeast Atlantic (Kjesbu et al. 1998). The mechanisms responsible for the determination of fecundity are well investigated at the individual level (Woodhead and Woodhead 1965; Kjesbu et al. 1991). Variations are mainly attributed to differences in fish size, food availability, and condition (Kjesbu et al. 1991, 1998; Lambert and Dutil 2000). However, it has proven difficult to transfer these relationships from the individual to population level to explain or predict interannual variation in average relative or size-specific fecundity. Seasonal variation in influencing factors and the associated problem of identifying the right time of sampling in the field seem to be the main complications. Consequently, factors influencing or covarying with fecundity (e.g., water temperature and prey biomass, Kjesbu et al. 1998) or total egg production (e.g., total lipid energy, Marshall et al. 1999) were used as indices. In the present study, a related approach was used to establish a model to predict relative fecundity. The final model was based solely on the relative prey availability during the early ripening period (fourth quarter), as the ambient water temperature did not contribute significantly. This observation differed to a certain degree from the results of Kjesbu et al. (1998) and Kraus et al. (2000). Though the relative fecundity in this study also tended to increase with rising temperature in the lower temperature range, the historically high temperatures in most recent years changed the relationship, indicated by a dome-shaped fecundity-temperature curve. However, as prey biomass and temperature covaried in the study by Kjesbu et al. (1998) and in the present study, it might be questioned whether temperature has a direct effect on fecundity or whether its effect is manifested through food availability and metabolic rate.

The ability of the fecundity model to predict relative fecundity was convincing also for data that were not used to establish the model except for two outlying years, i.e., 1978 and 1983 originating from Shapiro (1988). Anomalies in prey availability, water temperature, or FSSB could not explain these deviations, which may be ascribed to large individual variations in fecundity at low sample sizes. Based on this model, the predicted relative fecundity time series, PRF, was established and used as an alternative to ORF in the estimation of PEP.

The comparison of RSEP and RDEP with FSSB, PEP (PRF), and PEP (ORF) showed good agreement, with highly significant relationships between the stock-based estimates and the realized egg production. The PEP (PRF) performed better than the FSSB, but the best performance was observed for PEP (ORF), which was therefore considered the most accurate PEP estimate. This confirms a study of Köster et al. (2003) on Baltic cod, which showed a better accordance, based on a shorter time series of egg stage IA production, between RDEP and FSSB $\left(r^{2}=0.61 ; p<0.001\right)$ than between RDEP and SSB applied in standard assessments $\left(r^{2}=\right.$ $0.30 ; p<0.03)$. Their analysis showed only a limited improvement of the relationship by replacing FSSB with the potential egg production, which was, however, based on observed and interpolated relative fecundity $\left(r^{2}=0.63 ; p<\right.$ $0.001)$. In the present study, relating a revised and updated RDEP to PEP based on prolonged ORF time series without interpolation increased the explained variation by $21 \%$, and by $17 \%$ when using the RSEP. Although the data points especially for the RSEP are relatively few, these results clearly show the scope for improving indices of the reproductive potential in stock-recruitment relationships as also evidenced by Marshall et al. (1999). A frequent limitation to the estimation of PEP is the lack of fecundity time series. However, the predicted relative fecundity showed a relationship that convincingly reflected the observed variation in fecundity, and PEP based on PRF improved the FSSB as a measure of the reproductive potential considerably. At the same time, the model is so simple that it can be applied to both hindcast and forecast fecundity.

The agreement of the relationships between potential and realized egg production indicated that the variability in the time series reflected natural fluctuations rather than sampling noise. The decrease in explained variation and significance levels of the relationship between RSEP (RDEP) and the manipulated PEP time series with constant sex ratios, maturity, or fecundity further confirmed that the observed variation in these data represents true variability. This effect 
Fig. 6. Linear regressions of spawning stock biomass $(a$ and $b)$ and potential egg production (PEP) $(c$ and $d)$ versus year-class strength at age 2 for Eastern Baltic cod (Gadus morhua). ( $e$ and $f$ ) Multiple linear regression of PEP and the reproductive volume versus numbers of recruits at age 2. (e) Observed versus predicted recruitment; $(f)$ in relation to time. $\bigcirc$, observed values; lines, predicted values.
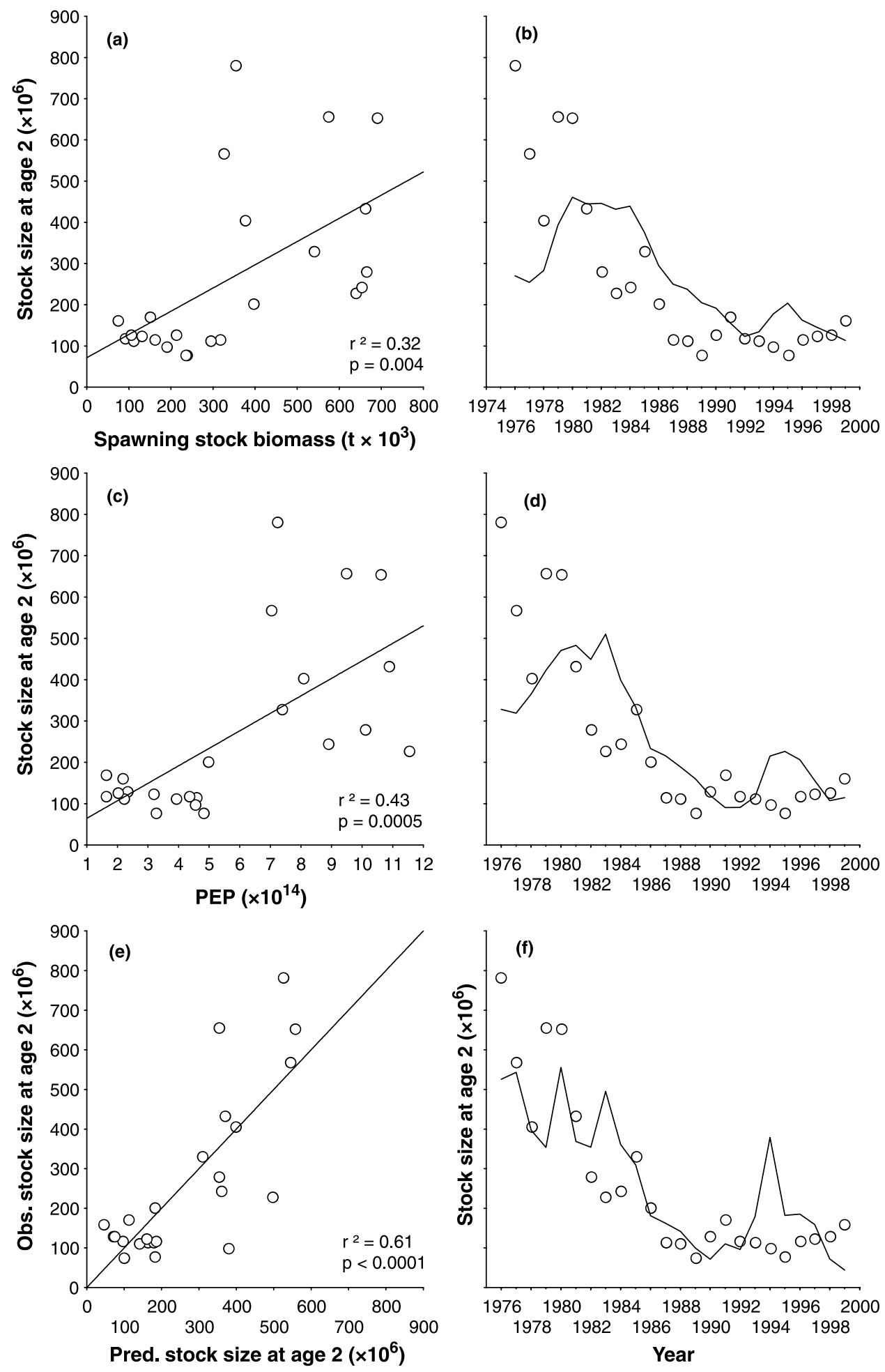

was most pronounced when a constant female maturity ogive was applied, and the PEP to RSEP relationship even lost significance. This agrees with the study of Köster et al. (2003) in which RDEP of stage IA was related to various measures of Baltic cod SSB. Their analysis showed a significant correlation between the RDEP and SSB when esti-

mated from variable maturity ogives $\left(r^{2}=0.30 ; p<0.03\right)$, but no correlation if SSB was based on the constant maturity ogive formerly used in routine assessment $\left(r^{2}=0.03 ; p=\right.$ $0.49)$. On the contrary, a sensitivity analysis to test the effects of different published maturity, sex ratio, and fecundity time series on Baltic cod egg production estimates (Mac- 
Kenzie et al. 1998) showed the largest impact for fecundity. The fecundity estimates used in these simulations were generated from various published and historic fecundity-size relationships, which in combination resulted in higher variation than in this study because of methodological differences. The results emphasize the importance of highquality data to estimate accurately the reproductive potential of a stock.

The variability in the maturity time series reflects substantial changes in growth and maturation related to substantial changes in stock size and prey availability that occurred within the years covered by the present study (Köster et al. $2001 b$ ). Thus, the proportions of mature cod within the age groups 2-5 were substantially higher in the 1990s than in the 1980s (Tomkiewicz et al. 1997; Cardinale and Modin 1999). Similarly, the relative fecundity tended to be lower in the early period of the study than in the later, and the fecundity model showed that these changes were related to the relative prey availability. The effect of removing the variability in sex ratio at age on the PEP to RSEP (RDEP) relationships was less pronounced and is likely to have other reasons. One is that the longevity of males in the stock is shorter than of females, and another is that males mature earlier than females (Tomkiewicz et al. 1997; Ajiad et al. 1999). If the age-specific differences in the sex ratio are not considered, the combined effect of these two causes will lead to underestimation of the PEP in a stock dominated by older age classes (1980s) and to overestimation of the PEP in a stock consisting mainly of young age classes (1990s).

The RSEP is expected to estimate the total realized egg production quite accurately. The Bornholm Basin is a welldefined spawning area because of its unique topography and the fact that cod eggs can only float within and below the halocline (Wieland 1995). A simulation study performed with a three-dimensional hydrodynamic model has demonstrated that advection, one of the major problems in egg surveys, is hardly any source of error (STORE 2001), enabling a quasisynoptic sampling of a large number of stations over the entire spawning area. Furthermore, additional information necessary to quantify egg production from abundance data is well established, e.g., temperature - stage duration relationships (Wieland 1995). As a high frequency of egg surveys is necessary to estimate RSEP, the number of years for which the RSEP could be determined is limited. These years, nevertheless, represent years from the 1980s with high FSSB, as well as recent years with low FSSB. The shape of RSEP curves and the Julian day of maximal daily egg production changed over the period as well as the total egg production. Changes are at least partially related to the FSSB structure being altered from domination by older specimens to domination by younger ones.

As the RSEP data points were relatively few, with rather clustered observations at low production indicating that additional factors not incorporated into the present PEP modeling approach affect the RSEP, the RDEP available for considerably more years was used as an alternative index. This time series confirmed the trends in the RSEP relationships to the FSSB and PEP, but the RSEP performed better than the RDEP. This was also expected as RSEP was only calculated for years with best survey coverage and the youngest egg stage IA was used, minimizing the impact of mor- tality. Although the scatter of the RDEP was larger, the data showed a more even distribution over the range of the independent variable confirming continuous relationships between both measures of the realized egg production and PEP.

The difference between PEP (ORF) representing the most reliable estimate of the potential egg production and the RSEP corresponds in principle to the loss of eggs as a result of atresia, fertilization failure, and mortality of eggs during early embryogenesis, but additionally it depends on the accuracy of the estimates. The loss of eggs was estimated to be $\sim 50 \%$ of the PEP, based on regression slopes or the average ratio. Studies on atresia, fertilization success, and mortality of cod eggs in the Bornholm Basin exist. Vallin and Nissling (1998) reported high average fertilization rates $(85 \%)$ for salinity above $11 \%$, which is typical for the spawning layers in the Bornholm Basin. Wieland (1995) estimated daily mortality rates for egg stage IA to range from 10 to $30 \%$ and a maximum duration of this stage of 3 days at $5^{\circ} \mathrm{C}$. Thus, the mortality throughout the half-stage duration, assumed as catch date, would range between $\sim 14$ and $\sim 40 \%$. Kraus (2002) observed a reduction of the annual potential cod egg production in the Bornholm Basin by atresia of 3.5\% in 1999. This indicates a relatively low importance of atresia at least for 1999 characterized by high prey availability and high fecundity. The cumulative egg loss resulting from the three processes thus ranges between 30 and $60 \%$, corresponding well to the egg loss estimated as the difference between PEP (ORF) and RSEP in the present study.

The extreme changes in cod stock size and prey availability were clearly advantageous for the establishment of the relationships in our analysis. The availability of reliable, independent sources of egg production to evaluate the quality of data used to estimate the reproductive potential was also fortunate, as the recruitment variability of Baltic cod is largely caused by environmentally induced mortality of eggs and larvae (Köster et al. 2001a).

Stock-recruitment relationships of Eastern Baltic cod have been subject to a number of studies (discussed in JarreTeichmann et al. 2000). Most earlier studies suffered from limited availability of data to establish reliable time series of reproductive potential. In the present study, we were able to estimate PEP of Eastern Baltic cod and prove its reliability as measure of the realized egg production. Using PEP as an alternative measure for reproductive potential explained $43 \%$ of the variation in recruitment, which is an improvement of more than $10 \%$ compared with the SSB routinely applied in stock-recruitment relationships (ICES 2002). The remaining scatter in the relationship suggested that environmental processes significantly affect the survival of early life stages and, hence, recruitment success. The reproductive volume defining the volume of water with sufficient salinity and oxygen content to allow successful cod egg development proved to be a significant factor for survival of cod eggs in the Baltic Sea (Plikshs et al. 1993; MacKenzie et al. 2000; Köster et al. 2001a). The combination of PEP and the reproductive volume as an index of the viable egg production that explained $61 \%$ of the variation in a stock-recruitment relationship confirmed these findings. Considering that hatching and the early larval stage were identified as additional critical phases affecting recruitment success of Eastern Baltic cod (Köster et al. 2003), the level of explained variation is high. 
The methodological approach applied in the present study is simple and largely based on regularly sampled data for routine assessment of the stock, which provides the basis for scientific advice on management of the stock (ICES 2002) and the MSVPA (ICES 2001a). A considerable amount of fecundity data exist or can easily be derived from the fecundity model. Similarly, reproductive volume time series are available and can be updated from the ICES hydrographic database. The simplicity of the combined PEP - reproductive volume index makes the method operational for routine assessment to improve stock-recruitment relationships and subsequent medium- to long-term stock projections. Introduction of more reliable stock-recruitment relationships also provide the opportunity to improve biological reference points used in management of the Eastern Baltic cod stock.

\section{Acknowledgements}

Most of the data collection and analysis presented in this study were carried out as part of international CORE (Baltic Cod Recruitment) and STORE (Stock Recruitment in the Baltic) projects. Participants from many institutes in the states surrounding the Baltic Sea have contributed with their data, results, and experience, which we gratefully acknowledge here. We especially thank Ali Müller, who initiated the fecundity work, and Ed Trippel and two anonymous referees for their valuable comments on the manuscript. The CORE (AIR2-CT94-1226) and STORE (FAIR-CT98-3959) projects received financial support from the European Commission. This paper does not necessarily reflect the views of the Commission and in no way anticipates the Commission's future policy in this area.

\section{References}

Ajiad, A., Jakobsen, T., and Nakken, O. 1999. Sexual difference in maturation of Northeast Arctic cod. J. Northw. Atl. Fish. Sci. 25: $1-15$.

Alheit, J. 1993. Use of the daily egg production method for estimating biomass of clupeoid fishes: a review and evaluation. Bull. Mar. Sci. 53: 750-767.

Beverton, R.J.H., and Holt, S.J. 1957. On the dynamics of exploited fish populations. Fish. Invest. Ser. II Mar. Fish G.B. Minist. Agric. Fish. Food 19.

Bleil, M., and Oeberst, R. 1996. The fecundity of cod in ICES Sub-Divisions 22, 24 and 25 in the years 1992 to 1995. ICES CM 1996/J:8.

Cardinale, M., and Modin, J. 1999. Changes in size-at-maturity of Baltic cod (Gadus morhua) during a period of large variations in stock size and environmental conditions. Fish. Res. 41: 285-295.

Daan, N. 1981. Comparison of estimates of egg production of the Southern Bight cod stock from plankton surveys and market statistics. Rapp. P.-V. Réun. Cons. Int. Explor. Mer, 178: 242-243.

ICES (International Council for the Exploration of the Sea) 1998. Report of the Baltic Fisheries Assessment Working Group. ICES CM 1998/ACFM:16.

ICES 1999. Report of the Study Group on Multispecies Model Implementation in the Baltic. ICES CM 1999/H:05.

ICES 2001a. Report of the Study Group on Multispecies Predictions in the Baltic. ICES CM 2001/H:04.

ICES 2001b. Report of the Baltic Fisheries Assessment Working Group. ICES CM 2001/ACFM:18.
ICES 2002. Report of the Baltic Fisheries Assessment Working Group. ICES CM 2002/ACFM:17.

Jarre-Teichmann, A., Wieland, K., MacKenzie, B.R.M., Hinrichsen, H.H., Plikshs, M., Aro, E. 2000. Stock-recruitment relationships for cod (Gadus morhua L.) in the Central Baltic Sea incorporating environmental variability. Arch. Fish. Mar. Res. 48(2): 97-123.

Kjesbu, O.S., Klungsoyr, J., Kryvi, H., Witthames, P.R., and Greer Walker, M. 1991. Fecundity, atresia, and egg size of captive Atlantic cod (Gadus morhua) in relation to proximate body composition. Can. J. Fish. Aquat. Sci. 48: 2333-2343.

Kjesbu, O.S., Witthames, P.R., Solemdal, P., and Walker, M.G. 1998. Temporal variations in the fecundity of Arcto-Norwegian cod (Gadus morhua) in response to natural changes in food and temperature. J. Sea Res. 40: 303-321.

Köster, F.W., Hinrichsen, H.-H., St. John, M.A., Schnack, D., MacKenzie, B.R.M., Tomkiewicz, J., and Plikshs, M. 2001a. Developing Baltic cod recruitment models. II. Incorporation of environmental variability and species interaction. Can. J. Fish. Aquat. Sci. 58: 1535-1557.

Köster, F.W., Möllmann, C., Neuenfeldt, S., St. John, M.A., Plikshs, M., and Voss, R. 2001b. Developing Baltic cod recruitment models. I. Resolving spatial and temporal dynamics of spawning stock and recruitment for cod, herring, and sprat. Can. J. Fish. Aquat. Sci. 58: $1516-1533$.

Köster, F.W., Hinrichsen, H.H., Schnack, D., St. John, M.A., MacKenzie, B.R., Tomkiewicz, J., Möllmann, C., Kraus, G., Plikshs, M., Makarchouk, A., and Aro, E. 2003. Recruitment of Baltic cod and sprat stocks: identification of critical life stages and incorporation of environmental variability into stock recruitment relationships. Sci. Mar. 66(Suppl. 3). In press.

Kraus, G. 2002. Variability in egg production of cod (Gadus morhua callarias L.) in the Central Baltic Sea. Ph.D. thesis, University of Kiel, Germany.

Kraus, G., Müller, A., Trella, K., and Köster, F.W. 2000. Fecundity of Baltic cod: temporal and spatial variation. J. Fish Biol. 56: 1327-1341.

Lambert, Y., and Dutil, J.D. 2000. Energetic consequences of reproduction in Atlantic cod (Gadus morhua) in relation to spawning level of somatic energy reserves. Can. J. Fish. Aquat. Sci. 57: 815-825.

MacKenzie, B.R.M., St. John, M.A., and Wieland, K. 1996. Eastern Baltic cod Gadus morhua: perspectives from existing data on processes affecting growth and survival of eggs and larvae. Mar. Ecol. Prog. Ser. 134: 265-281.

MacKenzie, B.R.M., Tomkiewicz, J., Köster, F.W., and Nissling, A. 1998. Quantifying and dis-aggregating the "spawner" effect: incorporating stock structure, spatial distribution and female influences into estimates of annual population egg production. ICES CM 1998/BB:11.

MacKenzie, B.R.M., Hinrichsen, H.H., Pliksh, M., Wieland, K., and Zezera, A.S. 2000. Quantifying environmental heterogeneity: habitat size necessary for successful development of cod Gadus morhua eggs in the Baltic Sea. Mar. Ecol. Prog. Ser. 193: 143-156.

Marshall, C.T., Kjesbu, O.S., Yaragina, N.A., Solemdal, P., and Ulltang, O. 1998. Is spawner biomass a sensitive measure of the reproductive and recruitment potential of northeast Arctic cod? Can. J. Fish. Aquat. Sci. 55: 1766-1783.

Marshall, C.T., Yaragina, N.A., Lambert, Y., and Kjesbu, O.S. 1999. Total lipid energy as a proxy for total egg production by fish stocks. Nature (London), 402: 288-290.

Marteinsdottir, G., and Thorarinsson, K. 1998. Improving the stockrecruitment relationship in Icelandic cod (Gadus morhua L.) by 
including age diversity of spawners. Can. J. Fish. Aquat. Sci. 55: 1372-1377.

Murawski, S.A., Rago, P.J., and Trippel, E.A. 2001. Impacts of demographic variation in spawning characteristics on reference points for fishery management. ICES J. Mar. Sci. 58: 1002-1014.

Pinhorn, A.T. 1984. Temporal and spatial variation in fecundity of Atlantic cod (Gadus morhua) in Newfoundland waters. J. Northw. Atl. Fish. Sci. 5: 161-170.

Plikshs, M., Kalejs, M., and Grauman, G. 1993. The influence of environmental conditions and spawning stock size on the yearclass strength of the Eastern Baltic cod. ICES CM 1993/J:22.

Ricker, W.E. 1954. Stock and recruitment. J. Fish. Res. Board Can. 11: $559-623$.

Rijnsdorp, A.D., Daan, N., van Beek, F.A., and Heesen, H.J.L. 1991. Reproductive variability in North Sea plaice, sole, and cod. ICES J. Mar. Sci. 47: 352-375.

Rothschild, B.J. 1986. Dynamics of marine fish populations. Harvard University Press, Cambridge, Mass.

Shapiro, L.A. 1988. Correlation between the quantity and quality of the gonads in the Baltic cod. Fisch. Forsch. 26(2): 66-69. [Translated from Russian by Can. Transl. Fish. Aquat. Sci. 5515, 1990.]

Shepherd, J.G. 1982. A versatile new stock-recruitment relationship for fisheries, and the construction of sustainable yield curves. J. Cons. Int. Explor. Mer, 40: 67-75.

Sokal, R.R., and Rohlf, F.J. 1995. Biometry. The principles and practice of statistics in biological research. W.H. Freeman \& Company, New York.

STORE (Stock Recruitment in the Baltic). 2001. Environmental and fisheries influences on fish stock recruitment in the Baltic Sea.
Consolidated Progress Report 01.01.2000-31.12. 2000 to the EU Commission, FAIR 983959 Parts 1 \& 2. European Commission, Directorate General XIV Fisheries, rue de la Loi 200, 1049 Brussels, Belgium.

Tomkiewicz, J., Eriksson, M., Baranova, T., and Feldman, V. 1997. Maturity ogives and sex ratios for Baltic cod: establishment of a database and time series. ICES CM 1997/CC:20.

Trippel, E.A., Kjesbu, O.S., and Solemdal, P. 1997. Effects of adult age and size structure on reproductive output in marine fishes. In Early life history and recruitment in fish populations. Edited by R.C. Chambers and E.A. Trippel. Chapman \& Hall, London. pp. 31-62.

Vallin, L., and Nissling, A. 1998. Cell morphology as an indicator of viability of cod eggs-results from an experimental study. Fish. Res. 38: 247-255.

Wieland, K. 1995. Influence of hydrography on vertical distribution and egg mortality of the Baltic cod (Gadus morhua callarias) in the Bornholm Basin, southern central Baltic. Ph.D. thesis, University of Kiel, Ber. Inst. Meeresk. Kiel No. 266.

Wieland, K., Jarre-Teichmann, A., and Horbowa, K. 2000. Changes in the timing of spawning of Baltic cod: possible causes and implications for recruitment. ICES J. Mar. Sci. 57: 452-464.

Woodhead, A.D., and Woodhead, P.M.J. 1965. Seasonal changes in the physiology of Barents Sea cod (Gadus morhua L.) in relation to its environment. 1. Endocrine changes particularly affecting migration and maturation. Int. Comm. Northw. Atl. Fish. Spec. Publ. 6: 691-715. 